\title{
Research on the Influence of Logistics Outsourcing on Logistics Efficiency
}

\author{
Yuehua Yuan ${ }^{1,}$, , Pengliang Qiao² \\ ${ }^{1}$ School of Guangxi University of Science and Technology, Guangxi 530000, China; \\ 2 School of Qinzhou University, Guangxi 530000, China. \\ a349515134qq.com
}

Keywords: Logistics outsourcing, logistics efficiency, influencing factors.

\begin{abstract}
In recent years, the logistics industry has developed rapidly with the advent of the supply chain era, and has also led the logistics outsourcing market, making it more and more mature. More and more companies have entrusted their own logistics business to professional third-party logistics companies. Make full use of the resource advantages of third-party logistics companies and improve their core competitiveness. China's logistics started late, the overall service capacity is limited, there is a lack of management experience, and logistics efficiency is low. These problems have constrained the development of China's logistics industry. Especially in the logistics outsourcing business, the level of practice is low and the activities are complex. It is impossible to fully control the logistics activities. There are uncertainties and the logistics distribution efficiency is low. In the research of logistics, the main research is the technology and personnel of logistics service providers. And on the equipment, there are few researches from the perspective of cooperative relations. The efficiency of logistics service providers with stronger capabilities is higher. Therefore, it is also very important to influence the relationship between the factors of cooperation relations on logistics efficiency, and it can improve the logistics efficiency in China.
\end{abstract}

\section{Introduction}

The rapid development of the logistics industry has attracted the majority of scholars to study logistics outsourcing. Logistics outsourcing can help companies to enjoy resources that are not available within the enterprise, help companies save manpower and material resources, and enable enterprises to develop their own core businesses with one mind and improve the efficiency of enterprises. This establishes a cooperative relationship between logistics demand enterprises and logistics supply companies. The prerequisite for long-term development of such partnerships is that the efficiency of third-party logistics companies can meet the standards of demanding companies, and the factors that influence the logistics efficiency are also used by many scholars. Researched, but the research from the customer's point of view is still relatively small, this article from the customer's point of view, analyzes the factors that affect the cooperative relationship between the business enterprise and the third-party logistics company. It is of great significance to improve the quality of logistics outsourcing services in China by providing guidance and reference for the establishment of good cooperative relationships between business enterprises and third-party logistics companies.

\section{Status Quo of Logistics Outsourcing Development in the Business Industry}

\subsection{Logistics Demand Has Great Market Potential.}

From the aspect of logistics outsourcing demand, the logistics demand market for the commerce and trade industry is very large. Logistics can guarantee the arrival of commodities in the hands of consumers. The commerce and trade enterprises are mainly SMEs, and the business involves more regions. The enterprises' own logistics cannot meet the needs of the enterprises. Business needs, at this time companies need to cooperate with third-party logistics companies, but there are still many companies more traditional, lack of logistics concepts, their own logistics, restricting the development of third-party logistics. 


\subsection{Increasing Strength of Logistics Outsourcing Supply Market.}

For third-party logistics, due to the strong support of the government, the development of modern logistics companies, the rapid development of the logistics industry, the government invested a huge amount of funds to establish a logistics city, and achieved a combination of the traditional wholesale market and modern trade logistics. However, due to the lower level of logistics demand of commercial and trade companies, the existing third-party logistics can meet the market demand.

In general, logistics service companies meet the logistics needs of the business sector at this stage. However, currently, the relationship between supply and demand for logistics outsourcing is extremely unstable. Most commercial and commercial enterprises are still in the initial stage of outsourcing. Enterprises also have the mentality of outsourcing their business to several participants to ensure "healthy" competition. The road of mutual cooperation between logistics service providers. Moreover, its cooperation level is low, service content is single, and the cooperation relationship between the two parties is not close. Only problems such as inconsistent opinions, inconsistent coordination, and trust crisis often occur. The two sides of the cooperation have only formed a transaction-type and contract-type relationship with the contract to control the two sides, and they can truly interoperate with each other. There is still little strategic alliance partnership to form an integration. Therefore, there are still some problems that need to be solved in the development of logistics outsourcing.

\section{Problems in Logistics Outsourcing in the Commerce and Trade Industry}

\subsection{Low Level of Logistics Services.}

On the one hand, the level of logistics demand is low, so most logistics companies have lower service levels. Their role is only to provide transportation services, and there are few other aspects. This low-level service determines the relationship of cooperation. At a low level, this phenomenon is not conducive to the development of the logistics industry, but it is also not conducive to improving the level of logistics. On the other hand, it is the quality of service. According to the survey, many logistics service companies' services are unsatisfactory for them. Logistics companies always proceed from their own interests. In order to reduce their own costs, facilities are incomplete and slow, and goods cannot be delivered in time. goods.

\subsection{Poor Management, Low Efficiency.}

Most logistics companies are small in scale, and rarely can be logistics backbone enterprises and leading enterprises. They do not have perfect service specifications and rules and regulations, they are not standardized in management, they do not have strong competitiveness, there is no standardized operating manual, and they lack of logistics. Monitoring of the service process, there is no way to quickly respond to the problem in the event of a quality accident. The lack of communication between logistics companies has led to low utilization of logistics vehicles and increased the cost of their own companies.

\subsection{Lack of Credit Management Mechanism.}

Logistics outsourcing is a service, and the service is characterized by the customer can not understand its pros and cons in advance, only to obtain service can judge its quality. In the logistics outsourcing market of Linyi City, the credit mechanism is not perfect. Enterprises cannot fully determine whether they are good or bad when choosing a logistics service provider. Once the contract is signed, the initiative of logistics service is held by the logistics service provider. Even after the breach of contract, it is seldom punished and there is no credit record. The low cost of breach of contract has weakened the service consciousness of some logistics companies. After signing a short contract and making a short-term commitment, the standard of service will decline, and commitments will not be realized. The access conditions of the main bodies of the logistics market are loose, and the doors are low. Many businesses that do not have business qualifications are influx. Most of the procedures are simple and financially confusing. The economic organization of the business owners is different, and the economic responsibilities that they undertake are also very different, which brings great risks to the economic interests of the logistics demanders. The Linyi logistics service market is promiscuous and lacks a reasonable and effective credit supervision mechanism. Fraud and fraud 
have occurred from time to time, severely undermining the operational norms of the logistics outsourcing market, and undermining the confidence of commercial and commercial enterprises in implementing logistics outsourcing. Some enterprises that have already implemented outsourcing have even begun to The plan turned to self-supporting and affected the long-term development of the logistics outsourcing market.3.4 Lack of long-term cooperation

Modern companies only use resources to cooperate with other companies and pursue the integration of industry interests. Many companies lack the awareness of long-term cooperation. The establishment of cooperative relations is generally short-term. Both parties only see the immediate interests, and it is difficult to obtain long-term benefits. Supply cooperation revenue.

\section{Countermeasures for the Development of Logistics Outsourcing in the Commerce and Trade Industry}

\subsection{Strengthen the Communication Between the Two Parties and Maintain the Continuous Development of the Relationship Between the Two Parties.}

Logistics efficiency is affected by communication to a great extent. Communication can reduce opportunism. However, most companies' communication techniques are unreasonable. As a result, communication between the two parties is difficult to conduct smoothly and communication is not smooth. As a result, the level of logistics services has not been improved. First, a correct communication mechanism should be established. Information asymmetry will lead to disagreement between the two parties. Therefore, it is necessary to establish a stable and reasonable communication mechanism to reduce the conflict between both parties and improve efficiency.

First, establish a correct communication mechanism. In the cooperative relationship between commercial enterprises and logistics companies, communication obstacles such as information obstruction and information distortion will make the communication between the business enterprise and the logistics enterprise crack. Therefore, we must establish stable and reasonable internal and external communication mechanisms to reduce internal and external conflicts and improve the efficiency of logistics operations.

Second, strengthen the effective use of information technology. Information technology has an important influence on information sharing and logistics synchronization of commercial and trading companies and logistics service companies. Therefore, companies should change the status of their own single-machine operations and improve information technology through the integration of logistics information technology in different departments and enterprises. The efficiency of the use of equipment provides a guarantee for the effective communication of logistics information between business enterprises and logistics service companies.

Third, make full use of all kinds of effective communication methods to transfer information as complete as possible. Different communication methods such as e-mail, telephone, video conference, and interview have different advantages and disadvantages for the transmission of different types of messages. The rational use of communication has a positive effect on the smooth cooperation between the two parties.

\subsection{Improve the Coordination Ability of Both Partners to Improve Overall Operating Efficiency.}

The lack of coordination between commercial and trading companies and logistics companies greatly reduces the efficiency of logistics outsourcing. Therefore, both parties should coordinate well, develop markets together, coordinate with each other, and cooperate with each other. The development of the two should be combined to achieve simultaneous development of both parties. The cooperation between various departments within the enterprise, fully share information, strengthen the internal standard management of the company, and form a good order.

\subsection{Enhance Mutual Trust.}

The most basic requirement for establishing good long-term cooperation between business enterprises and logistics companies is trust. The first is to establish a good credit environment. The current logistics market is chaotic and accidents frequently occur. The development of the logistics industry requires a healthy and stable environment. The government has stepped in to raise the barriers to entry into the logistics industry and establish a market access qualification certification 
mechanism. The second is to strengthen the construction of the credit system. The logistics industry association can establish a logistics information service platform, establish a credit evaluation system, increase the company's non-compliance costs, and reduce the risk of logistics outsourcing.

\subsection{Promote the Formation of Partnerships Based on Service Quality.}

A very important evaluation indicator for measuring the effectiveness of cooperation is the quality of service, and it is also an important indicator to measure the sustainable development of the relationship between the two parties. Business enterprises should formulate a corresponding rating system. Those with a higher rating will give priority to selection. Through a series of contracts, they will strengthen the cooperative relationship between commercial and trading companies and logistics companies, and let service providers know that only high-quality services can obtain long-term benefits.

In short, in logistics outsourcing, we must use service quality as a measure to promote the development of relations to high-level partnerships and form a true alliance of interests. In this kind of partnership, truly interoperability exists, mutual trust is maintained, commitments are safeguarded, and problems and negative attitudes toward opportunism are avoided in order to provide a higher quality of service and form a relationship that promotes quality. The benign cycle of the relationship between production and quality will eventually provide an effective guarantee for the lifting of the logistics efficiency of commercial and trading companies.

\section{Summary}

Based on the literature research on logistics outsourcing relations and related areas of logistics efficiency and the analysis of the factors affecting outsourcing relations, the factors affecting the relationship are identified based on the frequency of each factor: trust, communication, commitment, and opportunity. And set these four elements as elements of the concept. The two aspects of coordination and operational flexibility reflect the logistics cooperation capabilities of both parties, that is, coordination and operational flexibility are the influencing factors of the behavioral capability layer of this study.

This article analyzes the development status of both supply and demand markets in the logistics outsourcing of the commerce and trade industry. The development of suppliers can meet the demand side's logistics needs, but at the same time also found many problems, such as low level of logistics services, management confusion, lack of credit supervision mechanism, cooperation level Low and short cooperation periods did not form a true community of interests. This low-level partnership is also the main reason for inducing other unfavorable factors. By analyzing these issues, this paper proposes that trade and logistics industry logistics should strengthen communication in the future, reduce opportunism, increase trust, maintain commitments, improve collaboration capabilities, and develop partnerships to improve logistics efficiency.

\section{Acknowledgments}

China Malaysia logistics science and technology talent exchange and innovation platform construction (AD17195027).

\section{References}

[1]. Jong in Yoon, Yipping Le. Analysis of the transport efficiency of reverse logistics in Japan[J]. International Journal of Urban Sciences,2013,17(3).

[2]. Markovits-Somogyi, Boor. Assessing the logistics efficiency of European countries by using the DEA-PC methodology[J]. Transport,2014,29(2).

[3]. Leonora Battani, Antonio Rizzio, Giuseppe Vignola. Improving logistics efficiency of industrial districts: a framework and case study in the food sector[J]. International Journal of Logistics Research and Applications,2015,18(5). 
[4]. Sun Xu. Study on the Logistics Efficiency of Three Northeast Provinces Based on Three-Stage DEA[M].Springer Berlin Heidelberg:2012-06-15.

[5]. Pablo Coot-Millán,Xose Luís Fernández,Miguel Ángel Pesquera,Manuel Agüeros. Impact of Logistics on Technical Efficiency of World Production (2007 - 2012)[J]. Networks and Spatial Economics,2016,16(4).

[6]. Purim SiSwati, Nonagon Kronprasert, Kriangkrai Arunotayanun. Development of Decision Support System for Evaluating Spatial Efficiency of Regional Transport Logistics[J]. Transportation Research Procedia,2017,25.

[7]. Halve Shayne, Clemet T. Bjork, Ken Steger-Jensen, Noureddine Bouhmala, Umar Burk, Tor Erik Jensen, And Divined Berg. Measuring the contribution of logistics service delivery performance outcomes and deep-sea container liner connectivity on port efficiency[J]. Research in Transportation Business \&amp; Management,2018.

[8]. Siri Adolph, Patrick Kü bler,Joachim Metternich,Eberhard Abele. Overall Commissioning Effectiveness: Systematic Identification of Value-added Shares in Material Supply[J]. Procedia CIRP,2016,41.

[9]. Fedele Iannone. The private and social cost efficiency of port hinterland container distribution through a regional logistics system[J]. Transportation Research Part A,2012,46(9).

[10]. Xining Xiao, While He, Detain Fu, Mark Xu, Xiaoshuan Zhang. Applying CS and WSN methods for improving efficiency of frozen and chilled aquatic products monitoring system in cold chain logistics [J]. Food Control,2016,60.

[11]. Letitia Dabbling, Dina Rakotonarivo. The impacts of logistics sprawl: How does the location of parcel transport terminals affect the energy efficiency of goods' movements in Paris and what can we do about it. [J]. Procedia - Social and Behavioral Sciences,2010,2(3).

[12]. Daisuke Ichinose, Masashi Yamamoto, Junichiro Yoshida. Productive efficiency of public and private solid waste logistics and its implications for waste management policy[J]. IATSS Research,2013,36(2).

[13]. Alberto De Marco, Anna C. Caelian, Giulio Manga no, Francesca Perfecta. Factor Influencing Logistics Service Providers Efficiency' in Urban Distribution Systems[J]. Transportation Research Procedia,2014,3. 